Portland State University

PDXScholar

$4-8-2020$

\title{
Meta-Analysis of Tobacco Control Policies for Reducing Tobacco Consumption
}

Arya Kevin Naghdi

Portland State University

Follow this and additional works at: https://pdxscholar.library.pdx.edu/honorstheses

Part of the Public Health Commons

Let us know how access to this document benefits you.

\section{Recommended Citation}

Naghdi, Arya Kevin, "Meta-Analysis of Tobacco Control Policies for Reducing Tobacco Consumption" (2020). University Honors Theses. Paper 836.

https://doi.org/10.15760/honors.855

This Thesis is brought to you for free and open access. It has been accepted for inclusion in University Honors Theses by an authorized administrator of PDXScholar. Please contact us if we can make this document more accessible: pdxscholar@pdx.edu. 
Meta-Analysis of Tobacco Control Policies for Reducing Tobacco Consumption

By

Arya Naghdi

An undergraduate honors thesis submitted in partial fulfillment of the requirements for the degree of

Bachelor of Science

In

University Honors

and

Public Health Studies: Pre-Clinical

Thesis Advisor

Dr. Rajiv L. Sharma

Portland State University 


\begin{abstract}
:
The harmful effects of tobacco consumption and smoking have been well documented, and the literature is conclusive on their negative effects. However, there is still a great deal of discussion to be had on which policies and strategies can be employed to decrease smoking rates. Tobacco control policies used in the past included tobacco taxes, smoke free zones, anti-smoking media, sale to minors bans, and advertising restrictions on tobacco companies. Yet, it is still unclear which policies are most effective and least effective when it comes reducing smoking rates. A meta-analysis of 11 articles analyzing the effects of each policy has shown that tobacco taxation and smoke free zones are the most effective ways of reducing tobacco consumption while anti-smoking media, sale to minors bans, and advertising restriction tend to yield inconclusive results or lack potency. Implementing tobacco taxes and smoke free zones in conjunction with each other can greatly reduce tobacco consumption and offer plenty of health benefits due to reduced smoking rates.
\end{abstract}

\title{
Introduction:
}

A decrease in tobacco consumption can result in great health benefits and a reduction in various diseases caused by smoking tobacco. The article Global Effects of Smoking, of Quitting, and of Taxing Tobacco outlines the progress that has been made since the 1990's around the world in reducing tobacco consumption as well as the decrease in tobacco related diseases and deaths from such policies (Jha \& Peto, 2014). While the literature is fairly conclusive on the detrimental effects tobacco can have on individual and social health, there is still a discussion to be had on the various ways to curb tobacco consumption. Policies such as tobacco taxes, smoke free areas, laws on tobacco sales, anti-smoking media campaigns, and others have all been implemented in the past in one form or another. Tobacco taxes in particular have been cited as a 
prominent way to reduce smoking rates, particularly on populations in low socioeconomic status. On the other hand, taxation tends to have little effect when curbing tobacco consumption of heavy smokers, aboriginal, or other populations (Bader et al., 2011). There is often difficulty in maintaining control variables when examining tobacco consumption over time and certain populations react to certain policies differently. As a result, with all the research done on various tobacco control policies, it is still somewhat unclear which policies have been the most effective at reducing smoking thus far. Determining which policies work as well as what has little effect is important for public health policy moving forward and can yield vast health benefits due to lower smoking rates.

\section{Thesis Question:}

In my thesis, I seek to examine five different tobacco control policies and determine which have been effective in reducing tobacco consumption and smoking rates.

\section{Methods:}

A meta-analysis of various studies which examined the effects different tobacco policies have had on the prevalence of smoking, rate of smoking, and smoking cessation was conducted. Five tobacco control policies were examined: Tobacco taxation, smoke free zones, anti-smoking media, ban on sale to minors, and advertising restriction on tobacco companies. The 11 articles in the annotated bibliography were examined and their findings on the effectiveness of the tobacco control policy were used for the meta-analysis. This then allowed for a comparison of the effectiveness of each policy. Articles which were literature reviews of multiple studies done on a single tobacco control policy were preferred. This allowed for a more comprehensive examination of the effectiveness of a particular tobacco control policy to be analyzed.

\section{Results:}


Table 1: The table below provides a brief description of the effect the 5 different tobacco control policies had on tobacco consumption.

\begin{tabular}{|l|r|}
\hline Policy/Intervention & Effect On Tobacco Consumption \\
\hline Tobacco Tax & $\begin{array}{l}\text { Decrease in general population, particularly in youth, young } \\
\text { adults, and low socioeconomic status. Little effect on long term } \\
\text { smokers and aboriginals in one study (Bader et al., 2011). }\end{array}$ \\
& $\begin{array}{l}\text { Generally, a 10\% increase in real price causes a 4\% decrease in } \\
\text { consumption. }\end{array}$ \\
\hline Smoke Free Zones & $\begin{array}{l}\text { In the workplace: 29\% decrease in cigarette consumption } \\
\text { (Fichtenberg \& Glanz, 2002). }\end{array}$ \\
& $\begin{array}{l}\text { In the workplace: Median consumption decrease of 3.4\% and } \\
\text { median cessation increase of 6.4\% (Hopkins et al., 2010). }\end{array}$ \\
\hline $\begin{array}{l}\text { In college campuses: 3.3\% increase in cessation and 5.3 fewer } \\
\text { cigarettes smoked per day at Indiana University. 0.1\% decrease in } \\
\text { cessation and 0.3 fewer cigarettes smoked per day at Purdue }\end{array}$ \\
University (Seo et al., 2011).
\end{tabular}

\section{Discussion:}

The two policies which stood out as having the greatest impact on smoking were tobacco taxes and smoke free zones. The literature generally agrees that a $10 \%$ increase in tobacco prices results in a $4 \%$ decrease in tobacco consumption on average in western countries. One study examined the effect of tobacco taxation on various demographics in Australia and found that tobacco taxes had a particularly strong effect on youth, young adult, and persons of low socioeconomic status. These groups followed the trend of a $4 \%$ decrease in smoking prevalence with a $10 \%$ increase in price. However, tobacco tax legislation had little effect on decreasing 
tobacco consumption among aboriginal populations, as they only experienced a $0.73 \%$ decrease in tobacco consumption when the price rose $10 \%$ (Bader et al., 2011). Tobacco taxes also have a stronger effect on poorer individuals compared to the general population due to the regressive nature of the tax. Another study examined Australia's National Tobacco Campaign (NTC) which took place from May, 1997 to November, 2000 and consisted of tobacco tax legislation which had the effect of increasing the real price of tobacco by $25 \%$. This resulted in a $10.2 \%$ reduction in tobacco consumption among blue collar individuals and an $11.48 \%$ reduction in tobacco consumption among white collar individuals. The percentage of heavy smokers decreased from $26 \%-18 \%$. The average number of cigarettes consumed per day also decreased from 15.4 cigarettes to 14.1 cigarettes during the NTC. (Scollo et al., 2003).

Smoke free zones have also had a similarly strong, or perhaps stronger, effect at decreasing smoking prevalence. In one study, smoke free zones implemented in the workplace had the effect of reducing secondhand smoke as well as resulting in a $29 \%$ decrease in cigarette consumption on average. To achieve a similar decrease in cigarette consumption, a tobacco tax would have to raise the price of cigarettes $73 \%$ (Fichtenberg \& Glantz, 2002). However, another study which examined smoke free zones in the workplace found a much smaller impact from smoke free zones. This study found a median decrease of $3.4 \%$ in tobacco consumption and an increase in median smoking cessation of 6.4\% (Hopkins et al., 2010). A different study which examined smoke free zones on college campuses did not experience a drastic decline in smoking rates due to the policy. The study examined smoke free zones in Indiana University and Purdue University from 2007 to 2009. It found a 3.3\% decrease in the number of students who smoked cigarettes in Indiana University, but a $0.1 \%$ increase at Purdue University. During the same time, there was also a decrease of 5.3 cigarettes smoked per day at Indiana University and 0.3 
cigarettes smoked per day at Purdue University. Overall, the study determined that while the results were underwhelming, smoke free zones could still be utilized to decrease smoking rates at least in the area they were employed (Seo et al., 2011).

Anti-smoking media, sale to minors bans, and advertising restrictions appeared to have a smaller effect on diminishing the consumption of tobacco. Anti-smoking media campaigns conducted by the California Department of Health Services during the 60's and 70's were measured as having marginal effects on smoking prevalence and one study conducted from 1989-1993 found a 16\% decrease in cigarette consumption per capita. However, recent studies on the effects of anti-smoking media have seen little to no effect on smoking prevalence. The study concluded that while anti-smoking media could be useful, studies done on the topic consisted of too many confounding factors which were not accounted for, resulting in ambiguous results. Ultimately, more research was still needed to determine the effect of anti-smoking media (Liu \& Tan, 2009). Another study examined anti-smoking media campaigns conducted by the California Department of Health Services in the 1990's. The study surveyed 417 smokers to determine if anti-smoking media influence their smoking behavior in any way. It was found that only $6.7 \%$ of smokers interviewed were influenced by the anti-smoking media campaign. This was low compared to $38.2 \%$ who quit due to health related events or $17.7 \%$ who quit for no particular reason. Also, 30.9\% of interviewees had not seen or even heard of the anti-smoking media campaign. The study concluded that anti-smoking media could only have a small effect on tobacco consumption and the results found could have been inflated due to the nature of the survey questions (Popham et al., 1993).

Laws banning the sale of tobacco to minors have also had little effect on smoking rates. A study conducted in Massachusetts found that enforcement of tobacco sales to minors bans 
improved the percentage of venders complying with the law from $45 \%$ to $82 \%$ over 2 years. However, this had little effect on the prevalence of smoking among youth as minors were still able to obtain cigarettes by other means (Rigotti et al., 1997). Another study examined research from multiple countries around the world and found that such laws require strict enforcement. Sale to minors laws must target the multiple means which minors seek out cigarettes in order to decrease tobacco consumption. Without such measures, bans on tobacco sales to minors showed little to no effect on tobacco consumption (Nuyts et al., 2018).

Advertising restrictions placed on tobacco companies had the effect of decreasing cigarette consumption by $7.4 \%$, but only if a vast number of mediums for advertising were banned. Tobacco companies would simply switch the media for advertisement if the bans were limited in scope, resulting in little to no change in smoking behavior (Saffer \& Chaloupka, 2000). Another study found similar results. A $6.7 \%$ decrease in per capita consumption of cigarettes were experienced, but only if the advertising restrictions were dispersed across many media. Limited restrictions on tobacco advertising also showed no effect on tobacco consumption (Blecher, 2008).

\section{Limitations:}

During the research process, a few issues arose which somewhat undermined the results of the study. One weakness to the study was that confounding variables were at play in the articles examined. Articles used in the annotated bibliography mentioned how it was difficult to isolate a tobacco control policy's effects from others as legislation often resulted in the passing of multiple tobacco control policies at the same time. This culminated uncertainty as to whether the change in smoking rates were due to the tobacco control policy in question, or other extraneous factors. 
Another limitation to the study was that no universal measurement of effectiveness was able to be measured. Literature on the effectiveness of tobacco control policies often used different units of measurement such as cigarettes per day, prevalence of cessation, prevalence of smokers, prevalence of heavy smokers, and others. Some studies were also qualitative while others were quantitative. This made it difficult to quantify differences in the magnitudes of effectiveness between different policies. As a result, a more qualitative approach to determine which tobacco control policies were more effective was used.

A third weakness to the study was due to the fact that the populations examined often changed between articles. While this would in fact be a benefit when only one topic was of concern, this became problematic when the focus of the study also changed. Since different tobacco control policies were being examined against each other, having different populations between the different studies added an extra uncontrolled variable. This further complicated the study and put into question whether the difference in effect was due to different tobacco control policies, or different populations being examined.

\section{Conclusion:}

Overall, it can be shown that tobacco taxation and smoke free zones offer the greatest and most reliable decrease in tobacco consumption while anti-smoking media, sale to minors bans, and advertising restrictions lack in consistency and strength. However, there is some degree of uncertainty in the results due to confounding factors, different measurements being used, and different populations being examined. Future research could alleviate this issue by better quantifying the effect different tobacco control policies have, as well as observing the way different populations react to such policies. This can allow for a more comprehensive view of 
which tobacco control policies ought to be used to curb tobacco consumption among a certain population in question. 
Annotated Bibliography

Bader, P., Boisclair, D., \& Ferrence, R. (2011). Effects of Tobacco Taxation and Pricing on Smoking Behavior in High Risk Populations: A Knowledge Synthesis. International Journal of Environmental Research and Public Health, 8(11), 4118-4139. doi: 10.3390/ijerph8114118

This literature review examined various research articles on the effects tobacco taxation and pricing has had on the prevalence of smoking in various high-risk populations. The populations under question were youth, young adults, low socioeconomic status, long-term smokers, and Aboriginals. The article found that tobacco taxation was highly effective at deterring smoking among youth, young adults, and individuals in low socioeconomic status, but little evidence to show their effect on long-term smokers and Aboriginals. Aboriginals experienced a decrease of $0.73 \%$ in smoking rates even though there was an increase in the price of cigarettes by $10 \%$. Youth, young adults, and low socioeconomic status individuals more closely followed the $4 \%$ decrease in smoking rate with the $10 \%$ increase in price ratio.

Blecher, E. (2008). The impact of tobacco advertising bans on consumption in developing countries. Journal of Health Economics, 27(4), 930-942. doi: 10.1016/j.jhealeco.2008.02.010

The article is a literature review which examines studies done in developing countries on the effect advertisement restrictions have had on tobacco consumption. The studies examine advertisement expenditure and consumption to determine correlation, however there is still a debate in the discourse community as to whether this technique properly examines the effect of advertisement on smoking rates. The literature review found that comprehensive tobacco advertisement bans resulted in a $6.7 \%$ decline per capita consumption. Limited bans resulted in little to no change in tobacco consumption. The literature review concluded that it was still unclear the effect advertisement restrictions have on tobacco consumption. 
Fichtenberg, C. M., \& Glantz, S. A. (2002). Effect of smoke-free workplaces on smoking behaviour: systematic review. Bmj, 325(7357), 188-195. doi: 10.1136/bmj.325.7357.188

The article is a literature review which examines 26 studies on the effect of smoke free zones in the workplace. Smoke free zones not only prevent secondhand smoke, but also promote smoking cessation. Overall, there was a $29 \%$ decrease in cigarette consumption per employee on average. Compared to a tobacco tax, the price per pack would have to rise $73 \%$ in order to obtain the same decrease in cigarette consumption. It was found that employees smoked 3.1 fewer cigarettes per day. The article concludes that smoke-free workplaces are one of the most effective tools to decrease tobacco consumption and promoting legislation which expands smoke-free zones (particularly in the workplace) could be very beneficial.

\section{Hopkins, D. P., Razi, S., Leeks, K. D., Kalra, G. P., Chattopadhyay, S. K., \& Soler, R. E.} (2010). Smokefree Policies to Reduce Tobacco Use: A Systematic Review. ScienceDirect, 38(2), 275-289. doi: 10.1016/j.amepre.2009.10.029

The literature review article examined a total of 57 studies from 1976 - June 2005 which were on the topic of smoke-free policies and their effect on smoking cessation, tobacco use, and tobacco prevalence. These studies surveyed subjects and generally showed a decrease in tobacco use with only 3 studies showing a slight increase in smoking prevalence (1, 2, and 3\% respectively). The percent difference in smoking prevalence and cessation were put on a graph and the mean, and median were measured to show the overall trend. Smoke-free zones in the workplace resulted in a median decrease of $3.4 \%$ in tobacco use. Smoking cessation resulted in a median increase of $6.4 \%$. Only 5 studies showed a slight decrease in smoking cessation. Overall, smoke-free zones in the workplace were shown to be effective in reducing tobacco consumption and increase the rate of smoking cessation. 
Jha, P., \& Peto, R. (2014). Global Effects of Smoking, of Quitting, and of Taxing Tobacco. New England Journal of Medicine, 370(1), 60-68. doi: 10.1056/nejmra1308383

This review article examined global health trends in smoking and smoking policies. The article explains how smoking prevalence has decreased significantly over the past 20 years, but there has also been a sudden increase in E-cigarette consumption. The article also describes the health benefits from the decrease in worldwide smoking such as the decreases in smoking related illness and death. This article serves to describe the benefits of lower smoking rates in the introduction and is not used in the meta-analysis.

\section{Liu, H., \& Tan, W. (2009). The Effect of Anti-Smoking Media Campaign on SmokingBehavior: The California Experience. Annals of Economics and Finance, 10(1), 29-47. Retrieved from http://aeconf.com/Articles/May2009/aef100103.pdf}

The article is a literature review which examines the effectiveness of anti-smoking media campaigns at reducing smoking prevalence. Some studies in the 60's and 70's examined the effects anti-smoking media campaigns have had on smoking behavior and found a decrease. One study done in California found a 16\% decrease in per capita cigarette consumption from 19891993 and 9\% decrease from 1994-1996. However, the issue with such studies was that they were unable to separate the effects anti-smoking media had from other legislation that was also implemented to deter smoking. Other studies found little to no decrease in smoking rates and found that the media only affected those who were planning on quitting or prevented those looking to start smoking. There was little effect on the heavy smoker. The literature review concludes that anti-smoking media can still be useful in deterring smoking in the short run and long run, but more research needs to be done to see if it is worth the cost as it is not extremely effective. 
Nuyts, P. A., Kuijpers, T. G., Willemsen, M. C., \& Kunst, A. E. (2018). How can a ban on tobacco sales to minors be effective in changing smoking behaviour among youth? — A realist review. Preventive Medicine, 115, 61-67. doi: 10.1016/j.ypmed.2018.08.013

The article is a literature review which examined 26 quantitative, 5 qualitative, and 2 mixed method studies on the effect of sales to minors bans on the smoking rate among minors. Minors were generally surveyed for the studies. Studies chosen were from English speaking countries except Finland, Germany, Japan, The Netherlands, and Taiwan. The study found that sales to minors bans must meet several conditions (such as a strict enforcement) in order to have an effect on the smoking rates of youth. Otherwise, such a policy has little effect as minors have multiple ways of obtaining cigarettes and bypassing the law.

Popham, W. J., Potter, L. D., Bal, D. G., Johnson, M. D., Duerr, J. M., \& Quinn, V. (1993). Do anti-smoking media campaigns help smokers quit? Public Health Reports, 108(4), 510-

\section{Retrieved from https://www.ncbi.nlm.nih.gov/pmc/articles/PMC1403416/}

The article studied anti-smoking media campaigns conducted by the California Department of Health Services. 417 smokers were surveyed for the study. $6.7 \%$ of the smokers interviewed stated they were influenced to quit by the anti-smoking media campaign. However, this is low compared to $38.2 \%$ who quit due to health related events, $17.7 \%$ that quit for no particular reason, and $10.8 \%$ that quit because of the request of family members. $69.1 \%$ of the interviewees have seen or heard anti-smoking media campaign advertisements and $30.9 \%$ have not. $34.3 \%$ stated that the anti-smoking media campaign played a part in their decision to quit smoking. The article ultimately concluded that while anti-smoking media campaigns can have a small effect at reducing tobacco consumption, this could be inflated due to the method of surveys and interviews being used. 
Rigotti, N. A., Difranza, J. R., Chang, Y., Tisdale, T., Kemp, B., \& Singer, D. E. (1997). The Effect of Enforcing Tobacco-Sales Laws on Adolescents Access to Tobacco and Smoking Behavior. New England Journal of Medicine, 337(15), 1044-1051. doi:

\subsection{6/nejm199710093371505}

The article examined the effect enforcement of laws banning the sale of tobacco to minors had on the prevalence of smoking among minors. The study was conducted in Massachusetts with 3 communities as the control and 3 other communities as the intervention group with enforcement of the law. After 2 years of examining the 6 communities, it was found that while tobacco vendors began complying with the law at a greater rate $(45 \%$ in the control compared to $82 \%$ in the intervention), minors still had access to tobacco via other means, and the prevalence of smoking among minors had not changed significantly. The study discussed possible issues with sale to minors bans such as the increase use of fake ID's, minors lying about their age, or minors seeking cigarettes from non-minors, thus undermining the policy.

Saffer, H., \& Chaloupka, F. (2000). The effect of tobacco advertising bans on tobacco consumption. Journal of Health Economics, 19(6), 1117-1137. doi: 10.1016/s01676296(00)00054-0

The article is a literature review on 22 studies that have been done on the effect advertising bans have on tobacco consumption. The studies examined Organization for Economic Cooperation and Development (OECD) countries. Most studies found that advertising bans have no effect or a minor positive effect on tobacco consumption. Limited bans have little to no effect on tobacco consumption as only the media used changes, thus advertisement of tobacco is still present. Comprehensive bans of tobacco advertisement on all media is necessary in order to see a reduction in tobacco consumption. Overall, it was indicated by the data that 
comprehensive advertising bans result in a $7.4 \%$ reduction in cigarette use of the studies examined.

Scollo, M., Younie, S., Wakefield, M., Freeman, J., \& Icasiano, F. (2003). Impact of tobacco tax reforms on tobacco prices and tobacco use in Australia. Tobacco Control, 12(90002), 59ii-66. doi: 10.1136/tc.12.suppl_2.ii59 Tobacco Control 2003;12:ii59-ii66.

The article examined the effects Australia's National Tobacco Campaign (NTC) had on the rate of tobacco consumption in the country of Australia. The NTC was split into 3 phases of legislation which reformed tax law on tobacco: the first in November 1997, the second in November 1998, and the third in December, 1998 - November, 2000. Overall, the program had the effect of increasing the price of cigarettes by $25 \%$, as well as decreasing tobacco smoking prevalence, coming largely from the first 2 phases of the NTC. A decrease of $10.2 \%$ in tobacco consumption among blue collar individuals and $11.48 \%$ among white collar individuals was observed. A decrease of heavy smokers from 26\%-18\% from May, 1997 to November, 2000 was also found. The average number of cigarettes consumed per day decreased from 15.4 cigarettes to 14.1 cigarettes from May, 1997 to November, 2000. The article also stated that it has historically been shown in western countries that a $10 \%$ increase in real cigarette price results in a $4 \%$ decrease in consumption.

Seo, D.-C., Macy, J. T., Torabi, M. R., \& Middlestadt, S. E. (2011). The effect of a smokefree campus policy on college students' smoking behaviors and attitudes. ScienceDirect, 53(4-5), 347-352. doi: 10.1016/j.ypmed.2011.07.015

The article examined the effects of smoke-free campus policies on smoking rates among students attending Indiana and Purdue University. These students were surveyed in 2007 about their smoking habits and surveyed again in 2009 to see if there was a change. The study found 
that there was a statistically significant decrease of $3.3 \%$ in the number of students who smoked cigarettes in Indiana University, but an increase of $0.1 \%$ at Purdue University. At Indiana University there was also a decrease of 5.3 in the number of cigarettes smoked per day and 0.3 at Purdue University. Along with other data on the perception students had regarding the smoking policies on campus, the article concluded that smoke-free policies may still have a positive effect on campuses in reducing the rate and prevalence of smoking. 